\title{
Principaux critères de qualification des éléments préfabriqués en béton pour le bâtiment
}

\section{OBJET}

Cette recommandation indique les principales caractéristiques qui sont à vérifier sur les différents éléments préfabriqués en béton qui font partie, ou constituent l'ensemble du båtiment. Il s'agit d'éléments préfabriqués en béton armé, non armé ou précontraint de granulats normaux ou légers (excepté béton cellulaire).

\section{INTRODUCTION}

2.1. La vérification des caractéristiques des différents éléments préfabriqués, se pratique après la production de ces éléments, prêts à être livrés (avant de les mettre en montage). Les caractéristiques à vérifier et le nombre d'éléments doivent être choisis en fonction du but recherché pour les éléments.

TABLEAU

Principaux caiteres de qualification des elements prefabrioues pour le batiment

\begin{tabular}{|c|c|c|c|c|c|c|c|c|c|c|}
\hline \multirow{3}{*}{ Caractéristiques à vérifier } & \multirow{2}{*}{\multicolumn{2}{|c|}{$\frac{1}{\frac{\text { Eléments linéaires }}{\text { d'ossatures }}}$}} & 2 & 3 & 4 & 5 & 6 & \multirow{2}{*}{\multicolumn{3}{|c|}{$\begin{array}{l}\text { Documents } \\
\text { internationaux } \\
\text { existants }\end{array}$}} \\
\hline & & & \multicolumn{3}{|c|}{ Panneaux Verticaux } & \multirow{2}{*}{ Planchers } & \multirow{2}{*}{$\begin{array}{c}\text { Eléments } \\
\text { de } \\
\text { toiture }\end{array}$} & & & \\
\hline & Verticaux & Horizontaux & $\begin{array}{c}\text { Intérieurs } \\
\text { non porteurs }\end{array}$ & $\begin{array}{c}\text { Panneaux } \\
\text { porteurs }\end{array}$ & $\begin{array}{c}\text { Panneaux } \\
\text { extérieurs } \\
\text { non-porteurs }\end{array}$ & & & RILEM & iso & Autres \\
\hline 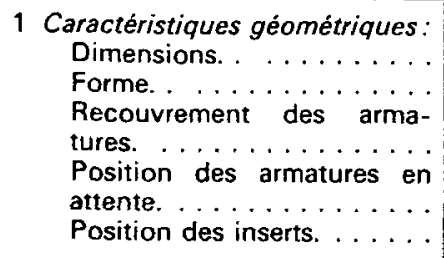 & $\begin{array}{l}+ \\
+ \\
+ \\
+ \\
+\end{array}$ & $\begin{array}{l}+ \\
+ \\
+ \\
+ \\
+\end{array}$ & $\begin{array}{l}+ \\
+ \\
0 \\
0 \\
+\end{array}$ & $\begin{array}{l}+ \\
+ \\
+ \\
+ \\
+\end{array}$ & $\begin{array}{l}+ \\
+ \\
+ \\
+ \\
+\end{array}$ & $\begin{array}{l}+ \\
+ \\
+ \\
+ \\
+\end{array}$ & $\begin{array}{l}+ \\
+ \\
+ \\
+ \\
+\end{array}$ & - & $\begin{array}{l}- \\
-\end{array}$ & \\
\hline 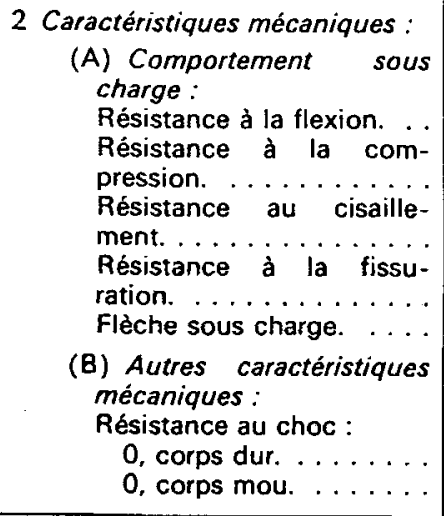 & $\begin{array}{l}0 \\
+ \\
0 \\
0\end{array}$ & $\begin{array}{l}+ \\
+ \\
+\end{array}$ & $\begin{array}{l}0 \\
0 \\
0\end{array}$ & $\begin{array}{l}+ \\
+ \\
0 \\
0\end{array}$ & $\begin{array}{l}0 \\
0 \\
0\end{array}$ & $\begin{array}{l}+ \\
+ \\
+ \\
+\end{array}$ & $\begin{array}{l}+ \\
+ \\
+ \\
+\end{array}$ & $\begin{array}{l}- \\
\overline{-} \\
- \\
-\end{array}$ & $\overline{-}$ & \\
\hline 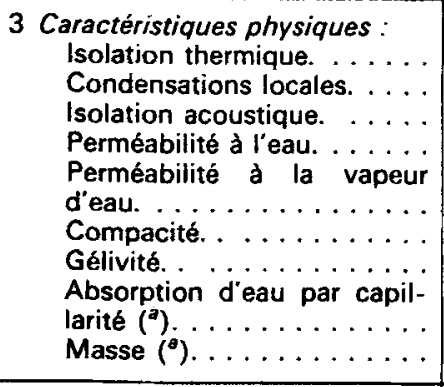 & 0 & 0 & 0 & $\begin{array}{l}+ \\
0 \\
+ \\
+ \\
+ \\
0 \\
+ \\
+ \\
+\end{array}$ & $\begin{array}{l}+ \\
0 \\
+ \\
+(b) \\
+\left({ }^{b}\right) \\
0 \\
+ \\
+ \\
+\end{array}$ & $\begin{array}{l}+ \\
0 \\
+\end{array}$ & $\begin{array}{l}+ \\
0 \\
0 \\
\\
+ \\
0 \\
+ \\
0 \\
+ \\
+\end{array}$ & & - & \\
\hline $\begin{array}{l}4 \text { Autres caractéristiques : } \\
\text { Aspect de surfaces. ...... } \\
\text { Variations dimensionnelles } \\
\text { dues à l'environnement. ... }\end{array}$ & $\begin{array}{l}+ \\
0\end{array}$ & $\begin{array}{l}+ \\
0\end{array}$ & $\begin{array}{l}+ \\
0\end{array}$ & $\stackrel{+}{\circ}$ & $\begin{array}{l}+ \\
0\end{array}$ & $\begin{array}{l}+ \\
0\end{array}$ & $\begin{array}{l}+ \\
0\end{array}$ & - & & \\
\hline
\end{tabular}

+ , Critères nécessaires selon l'emploi; 0 , critères facultatifs; -, en préparation. ( $\left.{ }^{\circ}\right)$ Dans le cas des éléments de béton de granulats légers.

(b) uniquement pour les éléments extérieurs. 